J. M. Davies MSc MD FRCPC, ${ }^{*}$ S. Weeks MB BS FFARCs, $\dagger$ L. A. Crone MD FRCPC, $\ddagger$ E. Pavlin MD\$

\title{
Difficult intubation in the parturient
}

Difficult or failed tracheal intubation is an important cause of anaesthetic-related maternal morbidity and mortality. The incidence of failed intubation in parturients is estimated to be as frequent as 1 in 500; that of mortality is unknown, although some 10-13 pregnant women in England, Scotland and Wales die each year because of anaesthetic-related complications. To prevent such catastrophes, all necessary monitors and equipment should be available, including that needed to deal with a failed intubation. Assessment of the patient may lead to preoperative recognition of a difficult airway; altered position. ing may be of help both in recognition and management. Furthermore, adequate assistance, correct use of cricoid pressure, and confirmation of tracheal intubation are fundamental to safe practice. Lastly, should the anaesthetist fail to intubate the patien's trachea, a management protocol is suggested.

\section{Key words}

ANAESTHESIA: obstetrical; COMPLICATIONS: intubation, tracheal, difficult, failed; INTUBATION: cricoid pressure; technique; EQUIPMENT: airway, artificial; LARYNX: cricoid; position.

From the Department of Anaesthesia: *Foothills Hospital, Calgary; †Royal Victoria Hospital, Montreal; + University Hospital, Saskatoon; §Harborview Hospital, Seattle.

Addresss correspondence to: Dr. J. M. Davies, Department of Anaesthesia, Foothills Hospital at the University of Calgary, 1403 - 29th St. N.W., Calgary, Alberta. T2N 2 T9.
Difficulty with tracheal intubation is a major factor in anaesthetic-related maternal complications although the incidence of difficult intubation is not precisely known. Lyons reported eight cases of failed intubation from a series of 2331 general anaesthetics given in a teaching hospital matemity unit between 1978 and $1983,{ }^{1}$ for an incidence of 1 in 291 or 0.34 per cent. The same year, Lyons and MacDonald reported the results of a survey which yielded two cases of failed intubation in 4260 obstetric general anaesthetics in the Yorkshire region in 1983. The incidence was 1 in 2130 or 0.05 per cent. ${ }^{2}$ Cormack and Lehane ${ }^{3}$ estimated an incidence of about 1 in 2000 of a "Grade 3 airway" (only epiglottis visible on laryngoscopy), which they postulated to be "the main cause of trouble." More recently, Samsoon and Young described an incidence of 1 in 283 or 0.35 per cent. ${ }^{4}$ (The four figures of 1 in 283,1 in 291, 1 in 2000, and 1 in 2130 suggest a composite incidence of about 1 in 500.)

Although none of these reports resulted in any maternal, fetal or newborn deaths, some 10-13 women in England, Wales and Scotland die each year as a direct result of complications from the administration of anaesthetics during childbirth. ${ }^{5}$ The report on Confidential Enquiries into Maternal Mortality in England and Wales reviews every death associated with pregnancy and childbirth and attempts to determine the cause. The number of maternal deaths is related to the number of maternities (mothers delivered) and not to the number of births. For the triennium 1982-1984, 243 deaths occurred during pregnancy or the 42 days of the puerperium. There were $1,883,753$ maternities in this time (Table I). Of the 243 deaths, 19 resulted from anaesthetic problems (Table II), the third leading cause of death. ${ }^{6}$ This represented a slight decrease from 22 in the 1979-1981 triennium. In ten patients, death occurred because of difficulty with tracheal intubation, leading to cardiac arrest, cerebral anoxia, or inhalation of stomach contents. Five other patients died as a result of pulmonary aspiration. The 1986 report $^{7}$ stated that many deaths resulted from "failure to take adequate precautions to prevent regurgitation from the stomach during endotracheal intubation following crash induction of anaesthesia." Unfortunately, in the latest report, the proportion of women dying from problems with airway management increased, from 55 per cent ${ }^{7}$ to 79 per cent. ${ }^{6}$ Similarly, in the state of Michigan, "failure to secure a patent airway was the 
TABLE I Maternal mortality, England and Wales 1982-1984

\begin{tabular}{lr}
\hline No. of maternitics & $1,883,753$ \\
No. of maternal deaths & 243 \\
No. of anaesthetic deaths & 19 \\
\hline
\end{tabular}

*During pregnancy or 42 days of the puerperium.

predominant cause of anesthesia-related maternal death ... since 1980." In that report, maternal deaths were defined as those occurting during pregnancy or within 90 days of termination of pregnancy, no matter what stage of pregnancy. From 1972 through 1984 there were fifteen deaths of which anaesthesia was the primary cause, representing 6.9 per cent of "direct" maternal deaths, or 0.82 per 100,000 live births. ${ }^{8}$

Repeated attempts at intubation increase the incidence of hypoxia, gastric acid aspiration and trauma; the anaesthetist must decide if further attempts are justified in the specific clinical situation. Hypoxia and death result from failure to oxygenate and ventilate, or from unrecognized intubation of the oesophagus, not from failed tracheal intubation. This paper is not intended to provide a comprehensive review of difficult intubation. Rather, it presents suggestions for appropriate anaesthetic equipment required in the delivery suite, preoperative assessment and intraoperative positioning of the parturient, application of cricoid pressure during induction of anaesthesia, and methods to confirm tracheal intubation in the parturient. Finally, management plans are described, should difficulty with tracheal intubation occur.

\section{Anaesthetic equipment}

Currently no mandatory requirements for anaesthetic equipment and patient monitoring exist in Canada. However, anaesthesia should be undertaken only with an anaesthetic machine which conforms to the Canadian Standards Association standards 9 and suction apparatus immediately available. According to the recommendations of the Canadian Anaesthetists' Society, monitoring equipment required for each anaesthetized patient includes apparatus to measure blood pressure with an appropriately sized cuff, stethoscope - either precordial,

TABLE II Maternal deaths associated with anaesthesia, 1982-1984

Total deaths

19

- difficulty with tracheal intubation

- inhalation of stomach contents

- cerebral anoxia secondary to cardiac arrest

(2)

- inhalation of stomach contents

- total spinal

- misuse of drugs

- misuse of apparatus

- haemorthage
TABLE II Suggested equipment for management of failed intubation*

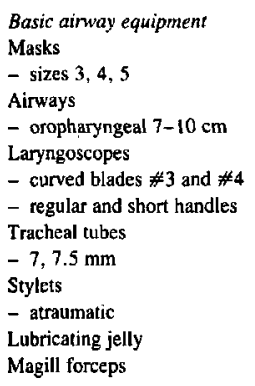

*Not for elective awake intubation.

oesophageal or paratracheal, ECG monitor with continuous audible signal recognition, and apparatus to measure temperature. ${ }^{10}$ Other required monitors include pulse oximetry ${ }^{\prime \prime}$ and measurement of end-tidal $\mathrm{CO}_{2} .^{12}$

Basic airway equipment (Table III) should be readily available, either on the anaesthetic machine or in the anaesthetic cart. In addition, extra equipment (Table IV), in the form of a difficult intubation equipment kit for dealing with a failed intubation, should be kept in one location in the Obstetric Operating Room(s) and checked

TABLE IV Suggested equipment for management of a failed intubation"

Difficult intubation kit

Airways

- oropharyngeal $7,8,9,10 \mathrm{~cm}$

- nasopharyngeal 6,7 mm

Laryngoscopes

- straight blades \#3 and $\# 4$

- polio blade

Tracheal tubes

- 5,5.5, 6, 6.5, $7 \mathrm{~mm}$

Bougie Stylet

- long, atraumatic, flexible tip to be used as a guide

Emergency tracheostomy set

- with tubes 5,6,7 mm

Cricothyrotomy sets ${ }^{\dagger}$

- percutaneous

- $2 \times 12$ or $14 \mathrm{G}$ plastic over metal cannula

- 3-way stopcock

- Oxygen tubing

$-6.0 \mathrm{~mm}$ tracheal tube connector

- surgical

- Scalpel with \#11 blade

- $5.0 \mathrm{~mm}$ tracheal tube

- commercial

Suction catheters

- \#12 French

* Not for elective awake intubation.

†Prepackaged and sterile. 
regularly. A box with a tear-off closure provides a suitable container. The list of articles in Table IV should not be thought to be exclusive. For example, some anaesthetists may wish to add such items as the Bellhouse angled laryngoscope with detachable prism. ${ }^{13,14}$ Others might choose to include some form of oesophageal obturator, although even its advocates rightly describe its hazards. ${ }^{15-17}$

\section{Patient assessment and positioning}

A recent review ${ }^{18}$ stressed the importance of anticipation of difficulties with tracheal intubation, as did the authors of the Michigan mortality report. ${ }^{8}$ Indeed, Endler et al. stated that "many complications ... from difficult or failed intubation, including death, could be avoided by careful and unhurried evaluation of all patients when they are admitted to the labor suite." An appropriate clinical history, including symptoms of gastro-oesophageal reflux and airway oedema, and preoperative physical examination are essential. In addition, detailed preoperative assessment of the airway is vital, in both the sitting and recumbent position. Structures to be examined include: jaw opening, dentition, mobility of the temporomandibular joint and neck, and distances from chin to larynx (suprahyoid notch) and from chin to chest. McIntyre listed six steps in the examination of the airway: lateral and anterolateral observation of the patient, anterior and lateral observation and palpation of the neck, maximal extension of the neck, maximal flexion of the neck, examination of the mouth/teeth/oral cavity, and determination of nasal patency. ${ }^{18}$

In the obstetrical patient requiring anaesthesia, anatomical variations such as a short neck, full set of teeth, micrognathia, and restricted neck movements may be compounded by obesity and large pendulous breasts. Also important is the association of laryngeal oedema with pre-eclampsia. ${ }^{19}$ However, as noted by Cormack and Lehane, the patient whose trachea is difficult to intubate may not be obvious when assessed preoperatively. For example, they emphasized that "what is not easy to see is the size and mobility of the tongue," one of the "three main factors" which can cause difficulty with tracheal intubation. ${ }^{3}$ This finding is in agreement with that of Mallampati et al. ${ }^{20.21}$ and Samsoon and Young. ${ }^{4}$

In addition, it is vital that the parturient be assessed in the recumbent position with left uterine displacement. Adjustments can then be made in her position before induction of anaesthesia, to make intubating conditions optimal. In a recumbent position on a standard operating table, the patient's head rests on a pillow about $7 \mathrm{~cm}$ high, with the neck slightly flexed and maximally extended at the atlanto-occipital joint. However, this may not be adequate to ensure rapid tracheal intubation in the pregnant or morbidly obese patient (Figure 1). Elevation

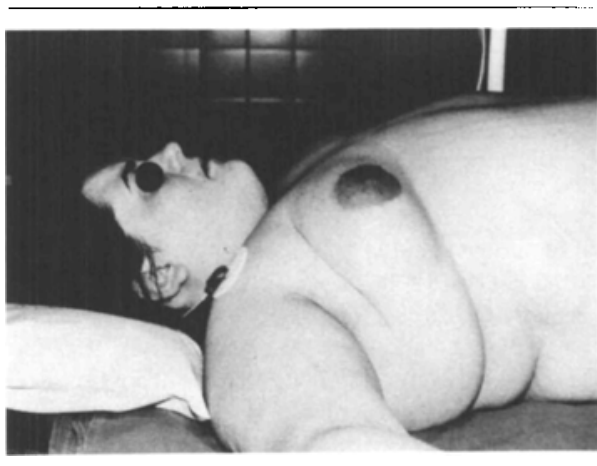

FIGURE 1 Standard positioning of obese parturient on operating table

of the thorax, shoulders and head may be necessary and can be achieved by using folded sheets or a pillow, bringing the anatomical axes into line (Figure 2). This may also avoid the problem of the laryngoscope handle abutting on the patient's chest. The use of a short-handled laryngoscope can be advantageous in this situation. Furthermore, awake laryngoscopy with local anaesthesia is of great value in assessment of the airway before induction of anaesthesia. If examination suggests potential difficulty with tracheal intubation, other simple measures can be an asset. These include elevating the operating table and moving the drapes far enough away so that there is room for the laryngoscope and an unobstructed view.

\section{Cricoid pressure}

Anaesthesia should never be started without an assistant who will perform cricoid pressure and remain at the patient's head until no longer required by the anaesthetist. Sellick's manoeuvre ${ }^{22}$ should be used during induction of general anaesthesia to decrease the possibility of regurgitation of gastric contents in the pharynx. The manoeuvre consists of temporary occlusion of the upper end of the oesophagus (hypopharynx) by posterior pressure on the cricoid cartilage against the body of the sixth cervical vertebra. Cricoid pressure must be applied by an assistant who has been appropriately instructed in the technique. Before induction, the cricoid cartilage is "palpated and lightly held between the thumb and second finger." 22 As consciousness is lost, "pressure is exerted on the cricoid cartilage mainly by the index finger."22 Pressure is not released until the tube is securely placed in the trachea, the cuff inflated and the chest auscultated to confirm bilateral air entry. Care must be taken that the assistant's hand not obstruct proper placement of the laryngoscope if the patient's neck is short and obese. 


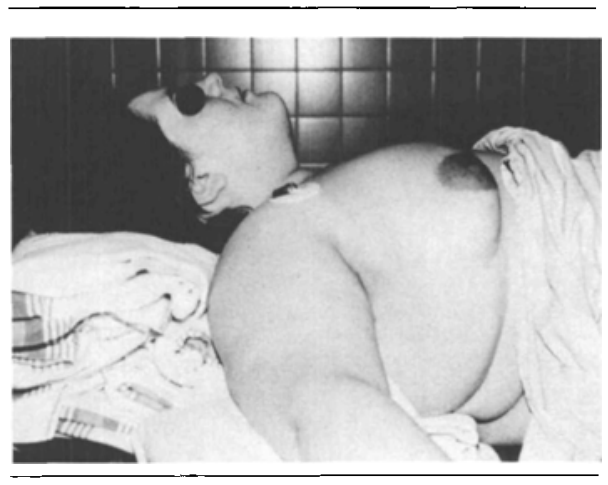

FIGURE 2 Improved "sniffing" position with elevation of torso and head.

Sellick also demonstrated that cricoid pressure is effective with a nasogastric tube in situ. ${ }^{23}$ The management of active retching during cricoid pressure is controversial. Oesophageal rupture, from "tethering" of the oesophagus at the cricoid during vomiting, is a theoretical possibility ${ }^{24}$ but has not been reported.

\section{Confirmation of tracheal intubation}

Adhering to these simple techniques should reduce catastrophic airway complications during emergency or elective anaesthesia for operative obstetrical procedures. Presumed tracheal intubation must be confirmed. A recent review by Birmingham et al ${ }^{25}$ provided a critique of 16 methods of detection of oesophageal intubation. These may be categorised into five types. Firstly, observation can be made of passage of the tube between the vocal cords, presence of condensation of water vapour in the tube's lumen, and movement of the chest and abdomen with ventilation. Secondly, techniques based on palpation include the feel of expelled air from the tube when the sternum is sharply pressed, and the characteristic tension and then refilling of the reservoir bag during manual ventilation. Thirdly, bilateral auscultation of breath sounds in the midaxillary lines of the chest helps to confirm, and epigastric auscultation to refute, tracheal intubation. Fourthly, use of pulse oximetry is very helpful, especially in women with darker complexions. Two American studies have shown a higher mortality rate from anaesthesia in women of black and other non-white races. ${ }^{8.26}$ However, preoxygenation may delay the onset of cyanosis, al though the pregnant woman will desaturate more quickly than her non-pregnant counterpart. Fifthly, measurement of end-tidal $\mathrm{CO}_{2}$ is the "most reliable and simple determination of proper tube placement" 25 and therefore should be used in all cases.
No matter which detection technique is used, each has been documented to fail, most often because of human error in interpretation. For example, in the parturient, limited expansion of the chest, difficulty with ventilation through the tracheal tube, and/or wheezing heard on auscultation of the chest immediately after presumed tracheal intubation may indicate oesophageal intubation. If there is any doubt as to the correct placement of the tube, then cricoid pressure should be continued, the tube should be removed and ventilation by mask resumed. In this situation, a predetermined plan of action should then be undertaken.

\section{Inability to intubate}

Difficulty with intubation in the parturient occurs most commmonly because of maternal anatomical abnormalities. These include problems with head and neck position (from reduced head extension ${ }^{13,14}$ or lack of proper positioning with the neck flexed and the head extended on the atlas ${ }^{3,27}$ ); the temperomandibular joint (limited mouth opening); ${ }^{3,13}$ the upper teeth; ${ }^{3}$ the tongue (bulk, ${ }^{13,14}$ displacement ${ }^{3}$ ); the mandible (shape, ${ }^{13}$ size $^{14}$ ); and the larynx (displacement). ${ }^{3}$

Added to these maternal factors is the problem of the inexperienced anaesthetist. Canadian practice does not allow "inexperienced junior anaesthetists" to provide unsupervised general anaesthesia for a parturient. However, the increase in the number of women receiving epidural anaesthesia for caesarean section ${ }^{28}$ means that fewer anaesthetists, consultants and residents, have experience with general anaesthesia, and therefore, in coping with difficult tracheal intubation.

The need for a plan, should difficulty occur with tracheal intubation, has been stressed by other authors and examples given. Some are detailed,,$^{13}$ others less so. ${ }^{3}$ The former is the refinement of two previous plans by Tunstall and readers are referred to the entire document, which also describes the airway after failed intubation. ${ }^{13}$ The plan of management described below is designed with North American anaesthetic practice in mind. That is, the patient is initially kept in the supine ("wedged") position, without either head-down or (further) left lateral tilt. However, as well described by Tunstall, a change in patient position may prove life-saving. ${ }^{13}$

The guidelines shown in Table $\mathrm{V}$ will not apply in every case and are intended as general recommendations. The importance of maintaining oxygenation of the patient is paramount. In all but the most urgent situations, e.g., maternal haemorrhage, severe fetal distress, the mother should be allowed to awaken after attempts at intubation have failed. However, in emergency cases, the decision to proceed with mask anaesthesia for caesarean section or forceps delivery will depend on the judgement of the 
TABLE V Failure to intubate the trachea: management protocol

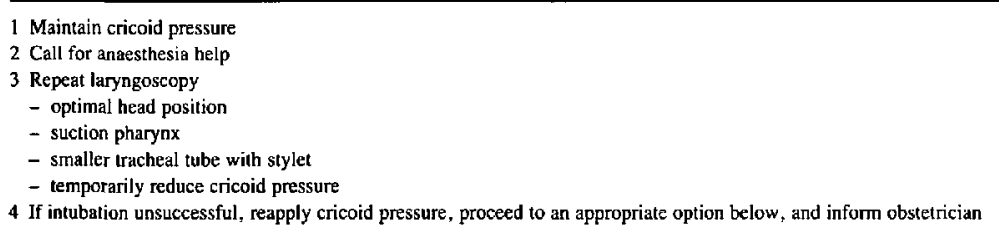

\begin{tabular}{|c|c|c|}
\hline \multicolumn{2}{|l|}{ Ventilation } & Ventilation impossible \\
\hline $\begin{array}{l}\text { Non-urgent case } \\
5 \text { If optimal attempt at laryngoscopy fails } \\
\text { and ventilation possible: } \\
\text { - maintain cricoid pressure } \\
\text { - ventilate with } 100 \% \text { oxygen } \\
\text { - allow drugs to wear off and patient to } \\
\text { awaken } \\
6 \text { Check status of fetus } \\
7 \text { Choose an altemative } \\
\text { - regional anaesthesia } \\
\text { - general anaesthesia } \\
\text { after awake intubation }\end{array}$ & $\begin{array}{l}\text { Urgent case } \\
\text { *5 If optinnal atternpt at laryngoscopy fails } \\
\text { and ventilation possible: } \\
\text { - maintain cricoid pressure } \\
\text { - continue ventilation with } 100 \% \text { oxygen and } \\
\text { an inhalational agent } \\
\text { - preferably, if patient resumes adequate } \\
\text { spontaneous ventilation, allow this to } \\
\text { continuc. } \\
\text { - alternatively, if patient apnoeic, } \\
\text { continue with mask ventilation until } \\
\text { adequate spontaneous ventilation } \\
\text { resumes } \\
6 \text { Inform obstetrician of need to expedite } \\
\text { surgery and to avoid fundal pressure }\end{array}$ & $\begin{array}{l}5 \text { If optimal attempt at laryngoscopy fails } \\
\text { and ventilation impossible: } \\
\text { - maintain cricoid pressure } \\
\text { - insent oropharyngeal airway } \\
\text { - insert nasopharyngeal airway } \\
6 \text { Call for surgical help - } \\
\text { - for surgical cricothyrotomy or } \\
\text { tracheostomy } \\
7 \text { lf still impossible to ventilate, assess } \\
\text { effect of releasing cricoid pressure and } \\
\text { consider turning patient on left side } \\
8 \text { If still impossible to ventilate: } \\
\text { - establish trins-tracheal airway: } \\
\text { percutancous cricothyroid needle } \\
\text { puncture or surgical cricothyrotomy } \\
\text { - establish trans-tracheal oxygenation } \\
9 \text { Once adequate trans-tracheal oxygenation } \\
\text { established, further management will } \\
\text { depend on patieltt's condition } \\
10 \text { Perform awake intubation or convert trans- } \\
\text { tracheal airway to formal surgical airway. }\end{array}$ \\
\hline
\end{tabular}

*No one anaesthetic technique has been documented to be superior in this situation.

anaesthetist and the clinical situation. After surgery, the patient must be informed and given a letter documenting the problem. Additionally, a medic-alert bracelet should be recommended.

\section{Inability to ventilate}

Cricothyrotomy may be necessary if oxygenation and ventilation cannot be achieved following attempts at tracheal intubation. Three methods can be used: needle cricothyrotomy with high pressure ventilation, cannulation using a cricothyrotomy device and surgical cricothyrotomy.

Needie cricothyrotomy and high pressure ventilation A 12- or 14-gauge needle and cannula are advanced through the cricothyroid membrane in a caudad direction. Entrance to the trachea is identified by the successful aspiration of air into an attached syringe. The cannula is then advanced over the needle and fixed to prevent kinking. Once the cannula is in place, three devices can be used to provide oxygenation and ventilation: the Sanders attachment for jet ventilation, a wall oxygen outlet, or the high pressure flush of an anaesthetic machine. Using the Sanders attachment, the high pressure hand-controlled ventilating device is attached to a wall oxygen outlet. The other end is attached to the Luer fitting of the cannula in the cricothyroid membrane. Jet ventilation is undertaken at about $40-50$ breaths per minute. Alternatively, the cannula's Luer fitting may be attached via a three-way stopcock to tubing connected to an oxygen flow meter set at 15 litres of $\mathrm{O}_{2}$ per minute. With intermittent interruption of flow using the three-way stopcock, this should also be sufficient to produce adequate oxygenation. ${ }^{29}$ The high pressure flush can also be used if a three-way stopcock is attached to the cricothyroid cannula. Oxygen tubing is connected to the common gas outlet circuit on 
the machine by means of a $6.0 \mathrm{~mm}$ tracheal tube connector. Oxygenation is then accomplished with intermittent use of the oxygen-flush button. The advantage of needle cricothyrotomy is that anaesthetists are familiar with injection through the cricothyroid membrane. Furthermore, although no special equipment is required, pre-assembly of one of the devices, before an emergency occurs, is useful.

\section{Cannulation using a cricothyrotomy device}

Several commercial devices are available for emergency cricothyrotomy (eg., "Melker Emergency Cricothyrotomy Set," "Nu-trake"). Directions for use vary with each device and anaesthetists should be familiar with what is available in their hospitals. In general, the cricothyroid membrane is located, the sharp point of the device is driven through the skin and membrane into the trachea, and the device inserted so that the distal end in the airway points down towards the lungs. A conventional Ambu bag or anaesthetic circuit is then attached to the external fitting. While the instructions sound simple, when the device is used by untrained individuals, there are both delays and complications, including failure to enter the trachea. Prior training is essential.

\section{Surgical cricothyrotomy}

After rapid skin preparation, the thyroid cartilage is stabilized with one hand, the cricothyroid space is identified and a transverse skin incision made over the cricothyroid membrane. After spreading the skin and subcutaneous tissue, the cricothyroid membrane is incised with a scalpel, ${ }^{30}$ the opening widened bluntly, and a small bore (5 or $6 \mathrm{~mm}$ ) tracheostomy or tracheal tube inserted. This more conventional surgical approach also requires training and in the emergency setting it is fraught with difficulty and complications.

No matter which device is used, the patient exhales normally through the larynx, rather than through the cricothyroid airway. In a wide variety of conditions causing partial upper airway obstruction (tumour, epiglottitis, etc.) patients have been able to exhale conventionally. ${ }^{29}$ However, placement of an oral airway and elevation of the mandible will help produce maximum expiratory airflow. Cricothyrotomy may be life-saving and may be continued during cardiopulmonary resuscitation. However, the technique is not without hazard, in particular the risk of extravasation of gas into the extratracheal tissues. $^{13}$

In conclusion, although a rare event, failed tracheal intubation in the parturient may be catastrophic. Careful preoperative assessment of the airway is vital. In addition, both a trained assistant for the anaesthetist alone and all necessary equipment must be available before any anaes- thetic is undertaken. If intubation is impossible but oxygenation and ventilation are adequate, then a decision must be made whether or not to proceed with mask anaesthesia. If intubation and ventilation are impossible then a surgical airway is necessary.

\section{Acknowledgements}

The authors gratefully acknowledge the many Canadian anaesthetists who gave advice on both the protocol and the paper.

\section{References}

1 Lyons $G$. Failed intubation. Anaesthesia 1985; 40: 759-62.

2 Lyons $G$, MacDonald $R$. Difficult intubation in obstetrics. Anaesthesia 1985; 40: 1016.

3 Cormack $R S$, Lehane J. Difficult tracheal intubation in obstetrics. Anaesthesia 1984; 39: 1105-11.

4 Samsoon GLT, Young JRB. Difficult tracheal intubation: a retrospective study. Anaesthesia 1987; 42: 487-90.

5 Anaesthetic Services for Obstetrics - a Plan for the Future. The Association of Anaesthetists of Great Britain and Ireland and The Obstetric Anaesthetists' Association. London, 1987.

6 Report on Confidential Enquiries into Maternal Deaths in England and Wales 1982-1984. London: Her Majesty's Stationery Office, May 1989.

7 Report on Confidential Enquires into Matemal Deaths in England and Wales 1979-1981. London: Her Majesty's Stationery Office, May 1986.

8 Endler GC, Mariona FG, Sokol RJ, Stevenson LB. Anesthesia-related maternal mortality in Michigan, 1972 to 1984. Am J Obstet Gynecol 1988; 159: 187-93.

9 2168.3-M84 Continuous flow inhalation apparatus (anaesthetic machine) for medical use. Toronto: Canadian Standards Association, 1984.

10 Guidelines to the Practice of Anaesthesia as Recommended by the Canadian Anaesthetists' Society. Toronto, 1987.

11 Amendment to the Guidelines to the Practice of Anaesthesia as Recommended by the Canadian Anaesthetists" Society. Toronto, June, 1988. (Required by 1 July, 1989).

12 Amendment to the Guidelines to the Practice of Anaesthesia as Recommended by the Canadian Anaesthetists' Society. Toronto, February, 1989. (Required by 1 July 1990).

13 Tunstall ME, Sheikh A. Failed intubation protocol: oxygenation without aspiration. Clinics in Anaesthesiology 1986; 4: 171-87.

14 Bellhouse $C P$, Dore $C$. Criteria for estimating likelihood of difficulty of endotracheal intubation with the Macintosh laryngoscope. Anaesth Intensive Care 1988; 16: 329-37. 
15 Tunstall $M E$, Geddes $C$. "Failed intubation" in obstetric anaesthesia. An indication for the use of the "Esophageal Gastric Tube Airway." Br J Anaesth 1984: 56: 659-61.

16 Corke CF, Jackson IJ. "Esophageal Gastric Tube Airway" - a potential hazard. Br J Anaesth 1985; 57: 930-1.

17 Tunstall ME. "Esophageal Gastric Tube Airway" - a potential hazard. Br J Anaesth 1985; 57: 931.

18 McIntyre JWR. The difficult tracheal intubation. Can Anaesth Soc J 1987; 34: 204-13.

19 Latto IP, Rosen $M$. Difficulties in tracheal intubation. London: Bailliere Tindall, 1985.

20 Mallampati $S R$. Clinical sign to predict difficult tracheal intubation (hypothesis). Can Anaesth Soc J 1983; 30: 316-7.

21 Mallampati SR, Gatt SP, Gugino LD et al. A clinical sign to predict difficult tracheal intubation: a prospective study. Can Anaesth Soc J 1985; 32: 429-34.

22 Sellick $B A$. Cricoid pressure to control regurgitation of stomach contents during induction of anaesthesia. Lancet 1961; 2: 404-6.

23 Sellick $B A$. The prevention of regurgitation during induction of anaesthesia. Proceedings of the First European Congress of Anaesthesiology, Vienna 1962; 1: 89.

24 Sellick $B A$. Rupture of the oesophagus following cricoid pressure? Anaesthesia 1982; 37: 213-4.

25 Birmingham $P K$, Cneney FW. Ward RJ. Esophageal intubation: a review of detection techniques. Anesth Analg 1986; 65: 886-91.

26 Rochat RW, Koonin LM, Atrash HK, Jewett JF, the Maternal Moraliny Collaborative. Maternal mortality in the United States: report from the Maternal Mortality Collaborative. Obstet Gynecol 1988; 72: 91-7.

27 Magill $I W$. Technique in endotracheal anaesthesia. $\mathrm{Br}$ Med J 1930; II: 817-9.

28 Ong B, Cohen MM, Cumming M. Palahniuk RJ. Obstetrical anaesthesia at Winnipeg Women's Hospital 1975-83: anaesthetic techniques and complications. Can J Anaesth 1987; 34: 294-9.

29 Weymuller EA Jr, Pavlin EG, Paugh D, Cummings $C W$. Management of difficult airway problems with percutaneous transtracheal ventilation. Am J Otol Rhinol Laryngol 1987; 96: 34-7.

30 Finucane BT, Santora AH. Principles of Airway Management. Philadelphia: FA Davis, 1988.

\section{Résumé}

Une intubation trachéale difficile peut être lourde de conséquence chez la femme enceinte et on estime qu'elle échoue une fois sur cinq cent dans cette population. On ignore le nombre de décès qui lui sont attribuables mais, bon an, mal an, de $10 \mathrm{~d} / 3$ femmes enceintes meurent de complications anesthésiques en Angleterre, en Ecosse et au Pays de Galles. Pour prévenir ces tragédies, il faut avoir sous la main tous les moniteurs et instruments permettant de pallier d une intubation difficile ou ratée. L'examen pré-opératoire de la patiente révélera souvent les difficultés à venir et la meilleure position pour les contourner. Une assistance éclairé pourra exercer d bon escienr une pression sur le cricoïde et aider à confirmer le succès de l'intubation. Enfin, nous vous proposons un plan d'action lorsque l' intubation s'avère impossible. 